Mеталлофиз. новейшие технол. / Metallofiz. Noveishie Tekhnol. @ 2017 ИМФ (Институт металлофизики 2017 , т. 39, № 4, сс. 477-490 / DOI: 10.15407/mfint.39.04.0477 им. Г. В. Курдюмова НАН Украины) Оттиски доступны непосредственно от издателя

Фотокопирование разрешено только

Напечатано в Украине.

в соответствии с лицензией

PACSnumbers: 62.20.mm, 62.20.mt, 75.78.Fg, 81.40.Np, 81.70.Bt, 81.70.Fy, 91.30.Px

\title{
On the Concentration Criterion of Fracture
}

\author{
L. R. Botvina and A. P. Soldatenkov
}

\author{
A.A. Baikov Institute of Metallurgy and Materials Science, R.A.S., \\ 49 Leninskii Ave., \\ 119334 Moscow, Russia
}

The kinetics of microcracks' accumulation at various stages of cyclic and static loading of specimens of the low-carbon grade 20 , medium-carbon grade 45 , and stainless $12 \mathrm{Kh} 18 \mathrm{~N} 10 \mathrm{~T}$ steels is studied. Concentration criterion of fracture ( $k$-criterion) characterizing the initiation of process of microcracks' coalescence and macrocrack formation as well as the characteristics of cumulative microcracks' distribution over their lengths are estimated. As shown, the $k$-criterion is associated with residual lifetime of a material by means of the power-law dependence. Some general regularities of defect interaction manifesting themselves at fracture of metal specimens are considered.

Key words: concentration criterion of fracture, damage accumulation, tension, microcracks' density, fatigue, residual lifetime.

Вивчено кінетику накопичення мікротріщин на різних стадіях циклічного та статичного навантаження маловуглецевої сталі, а також сталей 45 і $12 \mathrm{X} 18 \mathrm{H} 9 \mathrm{~T}$ у процесі розтягання. Оцінено концентраційний критерій $(k-$ параметр), що характеризує початок процесу злиття мікротріщин і формування макротріщини, а також характеристики кумулятивних кривих розподілу мікротріщин по довжині. Показано, що $k$-параметр пов'язаний степеневою залежністю із залишковою довговічністю матеріялу. Розглянуто деякі загальні закономірності процесів взаємодії дефектів, що проявляються при руйнуванні металічних зразків.

Ключові слова: концентраційний критерій руйнування, розтягання, накопичення пошкоджень, густина мікротріщин, утома, залишкова довговічність.

Corresponding author: Lyudmila Rafailovna Botvina

E-mail: botvina@imet.ac.ru

Please cite this article as: L. R. Botvina and A. P. Soldatenkov, On the Concentration Criterion of Fracture, Metallofiz. Noveishie Tekhnol., 39, No. 4: 477-490 (2017), DOI: $10.15407 /$ mfint.39.04.0477. 
Изучена кинетика накопления микротрещин на различных стадиях циклического и статического нагружения малоуглеродистой стали, а также сталей 45 и 12X18Н9Т в процессе растяжения. Оценены концентрационный критерий ( $k$-параметр), характеризующий начало процесса слияния микротрещин и формирования макротрещины, а также характеристики кумулятивных кривых распределения микротрещин по длине. Показано, что $k$-параметр связан степенной зависимостью с остаточной долговечностью материала. Рассмотрены некоторые общие закономерности процессов взаимодействия дефектов, проявляющиеся при разрушении металлических образцов.

Ключевые слова: концентрационный критерий разрушения, накопление повреждений, растяжение, плотность микротрещин, усталость, остаточная долговечность.

(Received December 13, 2016; in final version, March 31, 2017)

\section{INTRODUCTION}

The process of material fracture at any type of loading begins with the localization of plastic deformation near the structure inhomogeneity and stress concentrators. This process leads to the formation of plastic deformation zone, the defect accumulation in the zone and the subsequent initiation of macrocracks, whose growth regularities are determined by the fracture mechanics parameters. The development of this science field in recent decades has led to an understanding of these regularities under different loading conditions. However, regularities of damage accumulation in the deformation localization zone remain insufficiently studied, despite the importance and necessity of such studies related to the safe operation of structures and machine elements.

Significant contribution to the study of the regularities of microcracks accumulation process was made by researchers of Zhurkov's school. They obtained $[1,2]$ direct experimental evaluations of the kinetics of crack accumulation in polymers. The opalescence phenomenon at specimen loading was discovered, due to the light scattering because of the submicroscopic discontinuities appearance in physical system. These discontinuities are close to the light wavelength in size. Concentration, size and shape of these discontinuities in amorphous and crystalline polymers as well as the cracks' accumulation rate, which increases with the applied stress exponentially, were evaluated. Before fracture, the submicrocracks' concentration reached a critical value $\left(10^{15}-10^{16} \mathrm{~cm}^{-3}\right)$ that does not depend on the type of polymer and the stress state, the applied stress and the specimen durability.

In addition, it was found that the average size of cracks at the maximum concentration becomes comparable to the distance between them and the stress fields generated by these cracks overlap. It contributed to cracks' coalescence when reaching the maximum discontinuities' 
concentration. These studies led to the establishment of an important concentration parameter characterizing the damage accumulation process and determined as:

$$
k=1 /\left(L_{\mathrm{av}} \sqrt[3]{n}\right),
$$

where $L_{\text {av }}$ is the average microcrack length, $n$ is density.

To assess the criterion, which characterizes this process, the authors used the computational results on the cracks' interaction characteristics obtained by V. V. Panasyuk and B. L. Lozovyi [3, 4]. As a result, the interaction of two plane collinear cracks in an elastic medium begins at the moment when the ratio $(a / L)$ of the distance between the cracks to their length becomes less than 3. Experimental evaluation of criterion $a / L$ (or $R / L$ ) in the polymer specimens coincided with the predicted values. Thus, when $a / L>3$ cracks are isolated and do not affect each other and when $a / L<3$, the cracks interact and coalesce. T. L. Chelidze [5] obtained a similar criterion based on the percolation theory. Considering that in the three-dimensional case for the number $N$ of defects' concentration places with a radius $R$ of their influence sphere, the connectivity of individual spheres and an infinite cluster formation for these spheres occur in case when:

$$
(4 / 3) \pi N R_{\mathrm{C}}^{3}=2.7 \text { or } R_{\mathrm{C}} / r_{\mathrm{S}}=1.4,
$$

where $R_{\mathrm{C}}$ is the critical percolation radius, and $r_{\mathrm{S}}=\sqrt[3]{3 \pi N / 4}$ is the average distance between the origins of concentration $N$.

The authors [2, 6] have shown experimentally that, before the fracture, the average normalized distance between the cracks is constant and equal to:

$$
r_{\mathrm{S}} / l \approx \mathrm{const}=4.5,
$$

where $l$ is the average distance between the cracks. From Eq. (2), it follows that $r_{\mathrm{S}} / l=R_{\mathrm{C}} /(1.4 l)$.

It means the experimental Eq. (2) is similar to Eq. (1), and $R_{\mathrm{C}} /(1.4 l)=4.5$. Therefore, the critical percolation radius (or the interaction region of defects) is equal to $1.4 r_{\mathrm{S}}$.

In this paper, according to the data of the damage accumulation in structural grade 20 , grade 45 , and $12 \mathrm{Kh} 18 \mathrm{~N} 9 \mathrm{~T}$ steels at various stages of static and cyclic loading, the results of the damage characteristics evaluation and $k$-criterion are considered.

\section{MATERIALS AND RESEARCH METHODS}

The damage development analysis was carried out on specimens of 
TABLE 1. Mechanical properties of studied steels.

\begin{tabular}{c|c|c|c}
\hline Steel grade & $\delta, \%$ & $\sigma_{0.2}, \mathrm{MPa}$ & $\sigma_{\mathrm{ult}}, \mathrm{MPa}$ \\
\hline Grade 20 & $36.7 \pm 3.1$ & $283 \pm 4.7$ & $435.3 \pm 4.2$ \\
Grade 45 & $24.5 \pm 2.8$ & $362.9 \pm 16.5$ & $641.7 \pm 22.0$ \\
12Kh18N9T & $71.3 \pm 3.1$ & $234.2 \pm 4.1$ & $593 \pm 6.1$ \\
\hline
\end{tabular}

structural low-carbon grade 20, medium-carbon grade 45 and stainless 12Kh18N9T steels (in wt.\%, $0.07 \mathrm{C}, 18 \mathrm{Cr}, 9.5 \mathrm{Ni}, 0.35 \mathrm{Ni}$ ) [7-9], which are widely used in various technique fields and possessing different strength and plastic properties. Mechanical properties are shown in Table 1.

Tensile tests of standard smooth specimens $\left(220 \times 40 \times 6 \mathrm{~mm}^{3}\right.$ with the working portion of the specimen $80 \times 20 \times 6 \mathrm{~mm}^{3}$ ) were performed on Instron 3382 tensile-testing machine at room temperature and the deformation rate was $2 \mathrm{~mm} / \mathrm{min}$. The obtained 'load-displacement' diagrams were used for estimation of the specific work of plastic deformation $(w)$ as the area under the deformation curves (without the elastic part) divided into the volume of the working portion of the specimen.

The observations of lateral polished specimen surface by means of the optical microscope 'Olympus GX-51' equipped with a digital video camera were conducted at various tension stages. Using image analysis software, the microcracks' length $\left(L_{\mathrm{C}}\right)$, their number $\left(\Sigma N_{\mathrm{C}}\right)$, and the relative area $\left(S^{*}\right)$ occupied by them, i.e., the total area of microcracks divided into the image area, were measured in the neck region of the specimens. Crack length exceeding $0.5 \mu \mathrm{m}$ was measured because it was difficult to distinguish the cracks of shorter length from the large pores or pore chains. Based on the measurement results, damage accumulation curves in the coordinates 'the total number of cracks $\left(\Sigma N_{\mathrm{C}}\right)$ with length greater than the current length $\left(L_{\mathrm{C}}\right)$-the current crack length' were plotted, and the $k$-parameters were determined according to the modified equation (1): $k=1 /\left(L_{\mathrm{av}} \sqrt{n}\right)$, using the square root of the surface defect density instead of the cubic one, since the damage analysis was performed on the specimen surface.

\section{RESULTS OF THE STUDY}

\subsection{Damage Analysis of Low-Carbon Steel at Various Stages of Fatigue}

Figure 1, $a$ shows the microcracks' patterns observed on the polished surface of the specimens of low-carbon steel [10]. Using measurements on the patterns, the cumulative microcracks' number distributions on 
their lengths (Fig. 1, b) [11, 12] corresponding to different relative lifetime were plotted.

Apparently, the damage development leads to an increase in the number of microcracks on the early fatigue stages (upper plateau of the cumulative distribution curves increases) and their length on the final stage because of the adjacent defects' coalescence. At the relative durability $N / N_{\mathrm{f}}=0.85$ (i.e. the ratio of the number of loading cycles $N$ to the number of cycles $N_{\mathrm{f}}$ corresponding to the specimen fracture), the microcracks start to interact, thereby forming a macrocrack. It has an effect on the curves of cumulative damage (Fig. 1, $b$ ) described by the exponential function

$$
\Sigma N_{\mathrm{C}}=C \exp \left(-c L_{\mathrm{C}}\right)
$$

at the early stages of fatigue fracture, and by the power-law one

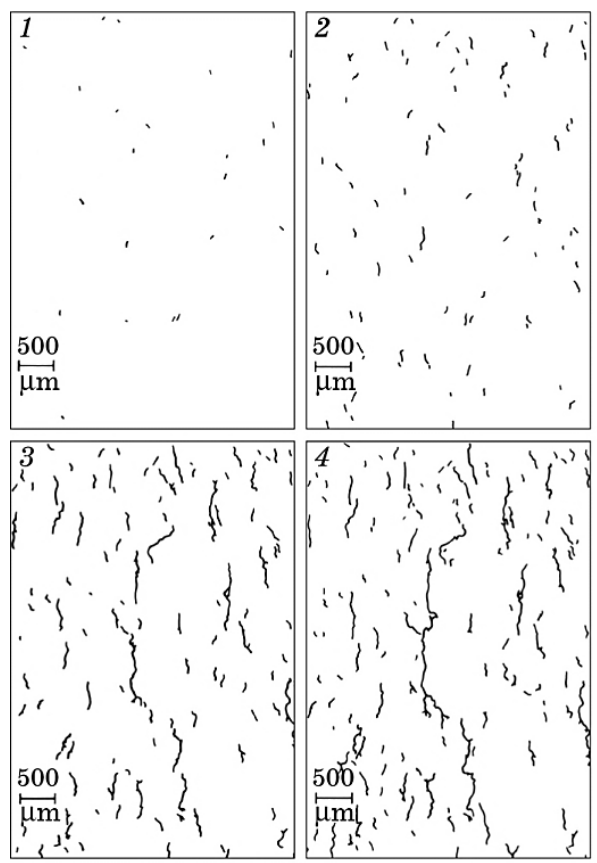

$a$

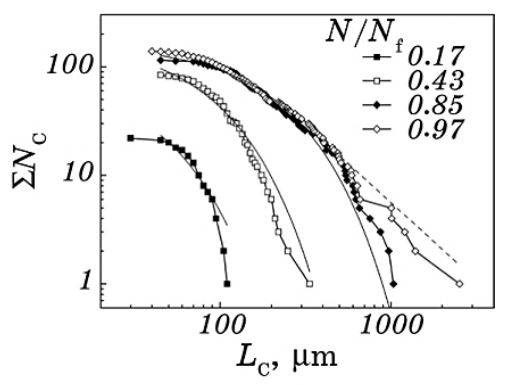

b

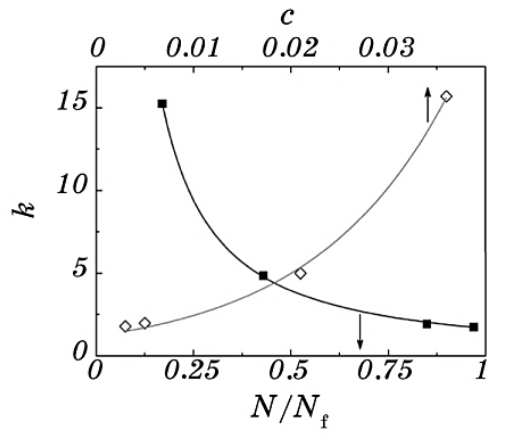

Fig. 1. Fatigue microcracks' patterns in a specimen of low-carbon steel (at $\sigma=333 \mathrm{MPa}, N / N_{\mathrm{f}}=0.17,0.43,0.85$, and 0.97 ) [10] (a), the cumulative microcracks' number distributions over their length plotted on these patterns [11-14] (b), and the dependences of $k$-parameter on the residual lifetime (bottom axes) and $c$-exponent in Eq. (3) (top axes) plotted according to [10, 15] (c). 


$$
\Sigma N_{\mathrm{C}}=B\left(L_{\mathrm{C}}\right)^{-b_{\mathrm{C}}}
$$

at the stage preceding the fracture; the exponents $c$ and $b_{\mathrm{C}}$ in these relations decrease with a lifetime increasing; $C$ and $B$ are constants. Onset of microcracks' coalescence leads to a sharp almost three-fold decrease in $k$-parameter obeying the power-law dependence (black curve in Fig. 1, c):

$$
k=A\left(N / N_{\mathrm{f}}\right)^{-d},
$$

where $A$ is constant. The rate of this reduction increases with the steel degradation caused by the development of delamination on the boundaries of the structural elements [15]. As follows from the grey curve in Fig. 1, $c$, the reduction of $k$-parameter is accompanied by a decrease in $c$-exponent in (3).

\subsection{Damage Analysis of Low-Carbon Grade 20 Steel at Various Tension Stages}

Figure 2 shows the microcracks' patterns observed on the polished surface of the specimen of low-carbon grade 20 steel at various tension stages $(a-c)$ [8] characterized by ratio of the current load $P$ to the yield load $P_{0.2}$, and the $k$-parameter dependences on the damaged surface portion $(d)$ and $c$-exponent $(e)$ in relation (3) plotted on these patterns.

Figure 2, $d$ shows that the sharp decrease in $k$-parameter takes place at the initial stage of discontinuities accumulation to $10 \%$ damage. After reaching the value, the parameter varies little and is almost independent on the grain size and the specimen thickness. However, the influence of specimen thickness affects the $k$-parameter dependence on $c$-exponent in (3) (Fig. 2,e). In this case, the rate of increase in the $k$ parameter for the $16 \mathrm{~mm}$-thick specimens is higher than for $4 \mathrm{~mm}$ thick specimens. This one shows the parameter sensitivity to the material local stress state, or rather, to the rise of the plastic strain constraint due to increase in the specimen thickness.

Plotting the cumulative microcracks' number distributions on their length in specimens of different thicknesses from grade 20 steel (Fig. 3 ) confirmed the previously noticed regularity at the analysis of cyclic damage (Fig. 1, $b$ ) associated with the change of the distribution function during damage development. At the initial tension stages, the cumulative microcracks' distributions are described by a simple exponential function, which changes by power-law function at the prefracture stage because of microcracks' coalescence and increase in the number of long microcracks. The solid curves 1 and 2 in Fig. 3 correspond to the Eqs. (3) and (4), respectively. The graphs show that the increase in specimen thickness results in a reduction of maximum mi- 

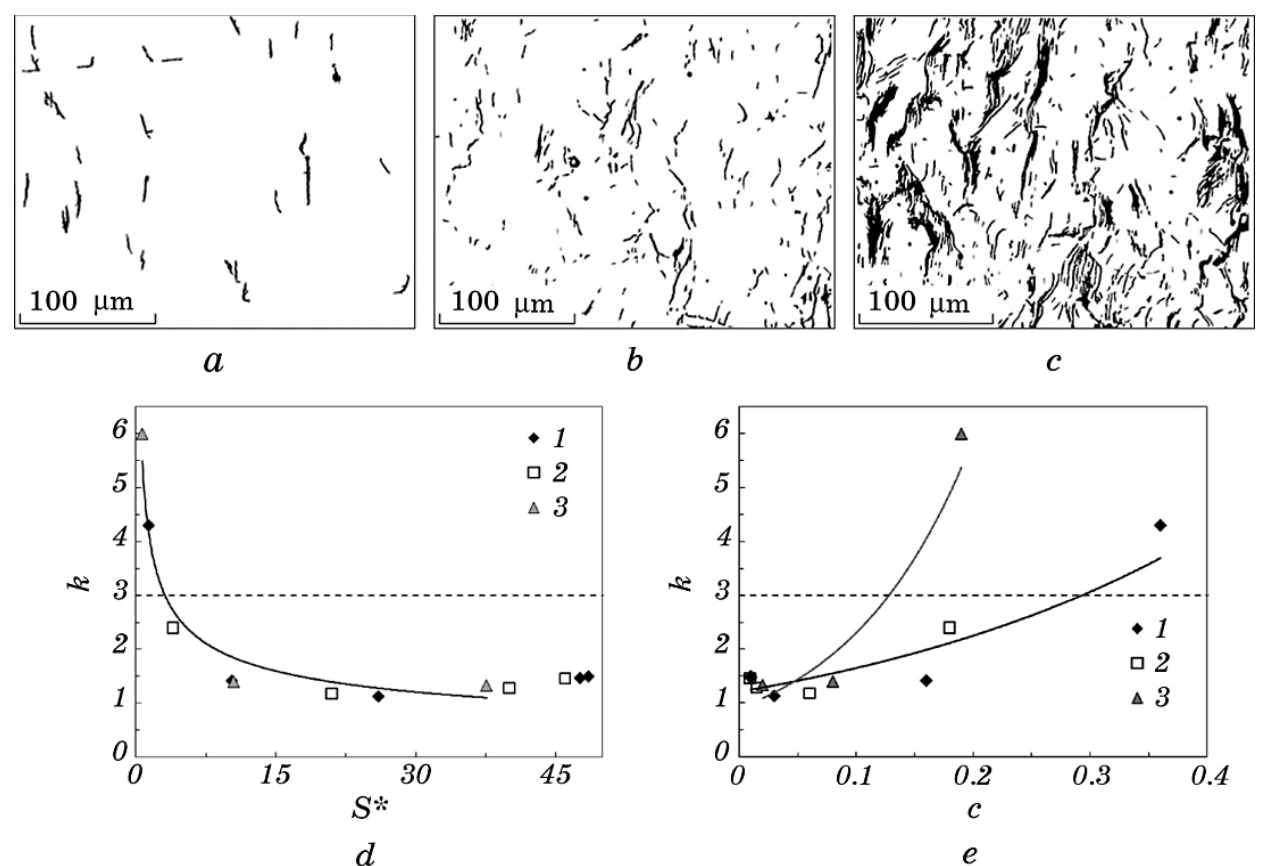

Fig. 2. Microcracks in a specimen with thickness of $4 \mathrm{~mm}$ of low-carbon grade 20 steel (grain size $d=97 \mu \mathrm{m}$ ) observed on various loading stages at $P / P_{0.2}$ equal to: $1.19(a), 1.38(b)$, and $1.52(c)$ [8], and the $k$-parameter dependences on the damaged surface portion $(d)$ and $c$-exponent $(e)$ in equation $(3)$ plotted for specimens with thickness of $4 \mathrm{~mm}(1-d=27 \mu \mathrm{m}, 2-d=97 \mu \mathrm{m})$ and $16 \mathrm{~mm}(3-d=97 \mu \mathrm{m})$.

crocrack lengths on both early and late stages of damage development.

In addition, the analysis of accumulated damage curves led to the conclusion [8] that the nature of approximating dependence is associated with a maximum length of microcracks. Therefore, at the stage of separate noninteracting-defects' accumulation with a maximum length not exceeding the grain size $\left(l_{\max } \leq d\right)$, the cumulative curves are described by an exponential relation. When the maximum length of microcracks becomes larger than grain size of about 3 times $\left(l_{\max } \geq 3 d\right)$, the accumulated damage curves are most likely to be described by a power-law function. In the region of intermediate microcrack lengths varying in the range of $(1-3) d$, the cumulative curves are approximated with equal probability by both exponential and power-law dependences.

In Refs. [7-9, 12], it was shown that the change in the cumulative microcracks' distributions is reflected in the similar change in the cumulative amplitude distributions of acoustic emission (AE) signals, which described by an exponential function at the beginning of loading 

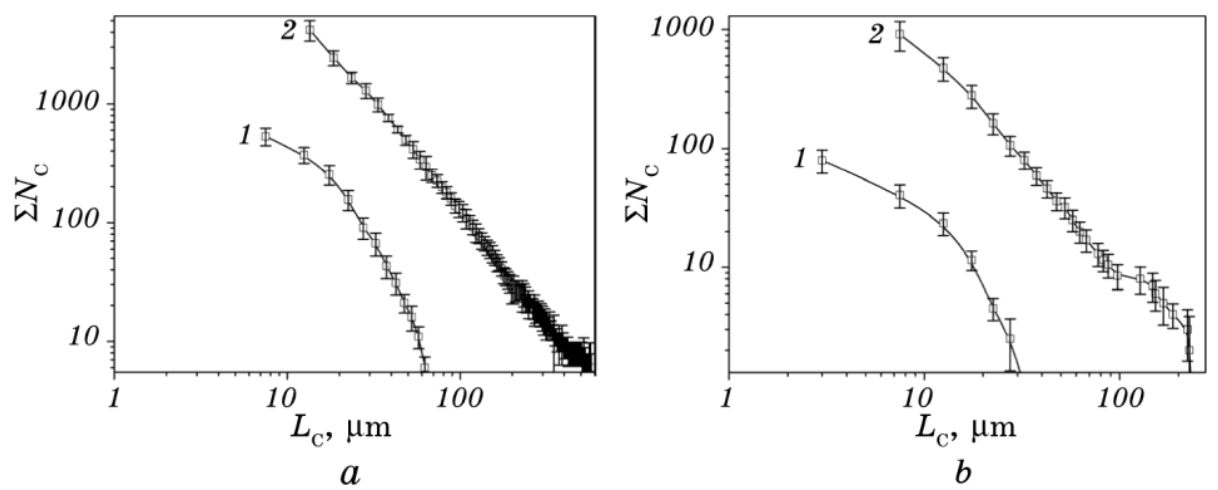

Fig. 3. The cumulative microcracks' distributions in the specimens of lowcarbon grade 20 steel with thickness of $6 \mathrm{~mm}(a)$ and $15 \mathrm{~mm}(b)$ at early (1) and final (2) stages of tension [8].

$\lg N_{\mathrm{AE}}=D-\exp \left(-c_{\mathrm{AE}} A_{\mathrm{AE}}\right)$, and then approached the power-law function $\lg N_{\mathrm{AE}}=B-b_{\mathrm{AE}} \lg A_{\mathrm{AE}}$, where $N_{\mathrm{AE}}$ is the total number of acoustic emission signals with an amplitude $A_{\mathrm{AE}}$ exceeding a given one.

\subsection{Comparative Analysis of the Damage Accumulation in Three Steels with Different Microstructures under Tension}

As seen from Fig. 4, $a-c$, the microcracks' patterns in the low-carbon grade 20 and medium-carbon grade 45 steels differ from the microcracks' patterns observed in stainless steel. In specimens of ferritepearlitic steels, the microcracks are oriented at an angle of $45^{\circ}$ to the loading axis, while in specimens of the austenite steel they are parallel to the loading axis. However, the $k$-parameter dependence on the damaged surface portion observed in Fig. 2, $d$ is the same and corresponds to the power-law dependence $\left(k \propto\left(S^{*}\right)^{m}\right)$ exhibiting a plateau at achieving $10 \%$ damage.

The power-law dependences also connect $k$-parameter and a specific work of plastic deformation estimated on area under the deformation curve divided into the volume of the working portion of the specimen (Fig. 4,e).

It is worth noting that the most parts of the diagrams in Figs. 2 and 4 are below the level defined by the $k$-criterion and equal to 3 .

\section{DISCUSSION OF THE RESULTS}

Some of the above-described dependences of microcracks' accumulation in metal specimens are revealed at other scale levels that allows assuming the existence of general regularities characterizing the de- 


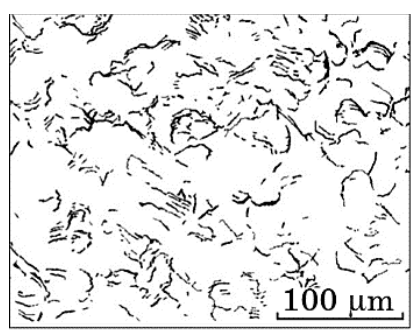

$a$

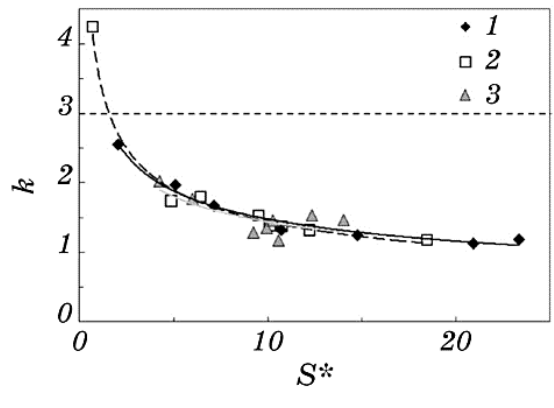

$d$

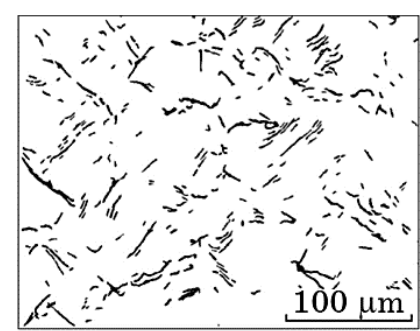

$b$

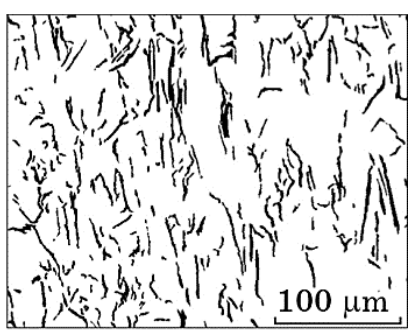

c

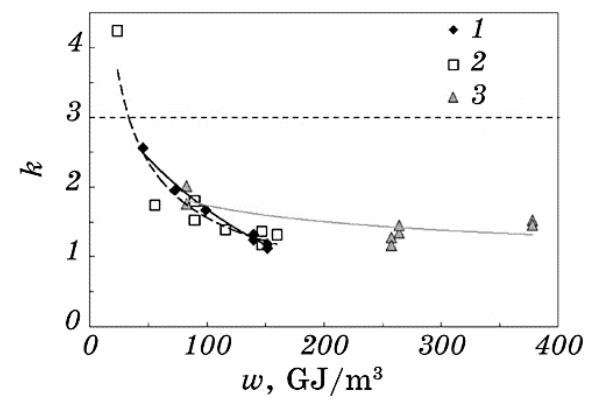

e

Fig. 4. Microcracks' patterns on the polished surfaces of specimens of the lowcarbon grade $20(a)$, medium-carbon grade $45(b)$ and stainless $12 \mathrm{Kh} 18 \mathrm{~N} 9 \mathrm{~T}(c)$ steels observed under tension conditions at close relative strain values $\left(\varepsilon / \varepsilon_{\mathrm{f}}\right)$ and the $k$-parameter dependences on the damaged surface portion $\left(S^{*}\right)(d)$ and specific work of plastic deformation $w(e)$. Markers 1, 2, and 3 correspond to the low-carbon grade 20 , medium-carbon grade 45 and stainless $12 \mathrm{Kh} 18 \mathrm{~N} 9 \mathrm{~T}$ steels, respectively.

fects' accumulation that will be considered below.

1. It is known that the basic equation in seismology is the Gutenberg-Richter law [16], which relates the number of seismic events with energy:

$$
N=A E^{-b}, \lg N=-b \lg E+C=-b M+C,
$$

where $N$ is the number of seismic events (earthquakes) with energy equal to or greater than $E, M$ is magnitude $(M=\lg E), C$ is constant, and $b$ is slope of the accumulated earthquakes number dependence on magnitude. In seismology, the curve plotted in the coordinates 'accumulated events' number-magnitude' and obeying this law in its middle part is referred to as 'cumulative distribution curve' or 'recurrence curve'. Usually, the Gutenberg-Richter law plotted for the most regions in the world is linear in the semi-log axes. However, the recurrence curve plotting for the individual regions or different time periods prior to the earthquake revealed a knee on the curve with a de- 


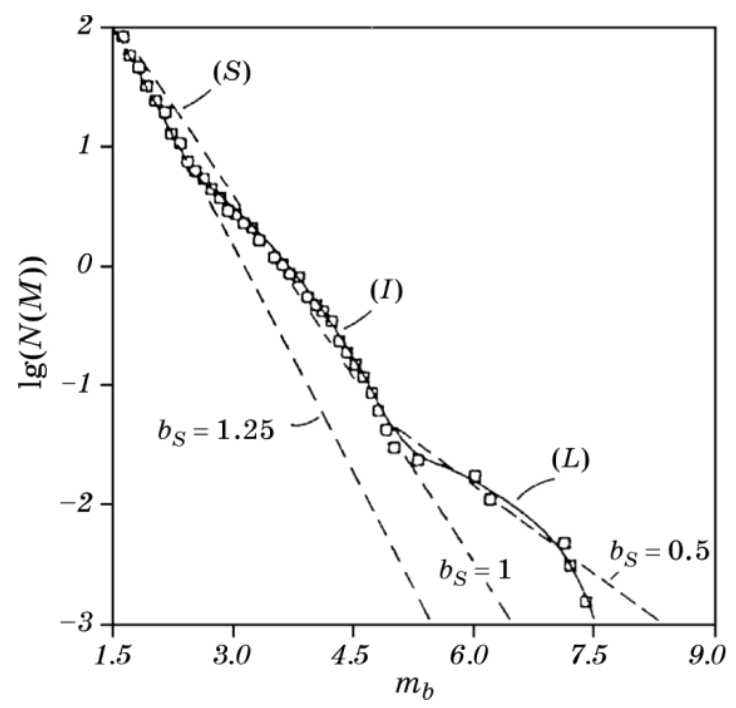

Fig. 5. Recurrence curve characterizing seismic activity in the New Madrid zone: $S, I, L$ are small, intermediate and large events, respectively; $b_{S}$ is exponent in the Gutenberg-Richter law [17].

crease in slope before a seismic event with large magnitude (Fig. 5). It is similar to inflection point in the cumulative microcracks' distribution curve (Fig. 1, b) before the fatigue macrocrack formation [11-14].

Since the energy released during an earthquake is proportional to the length of fault arisen, the cumulative faults' number distributions over length are described by the relation similar to the GutenbergRichter law (and equation (4) of the microcracks' accumulation) with an exponent values varying in different regions of the world.

Recurrence curves plotted on the acoustic emission data registered during deformation of metal specimens also show a decrease in the slope of the curves before the fracture [7-9, 12].

2 . The authors of [18] used a concentration criterion of fracture for assessing the degree of clusterization, i.e., grouping of seismic events or acoustic emission signals in laboratory testing of rocks. A cluster is assumed to be formed by two or more acoustic signals, if the distance between signal hypocentres and time between the signals are less than the critical values of $R_{\mathrm{cr}}\left(R_{\mathrm{cr}}=3 R+B\right)$ and $T_{\mathrm{cr}}\left(T_{\mathrm{cr}}=\alpha \cdot 10^{\beta\left(K_{\mathrm{i}}-K_{0}\right)}\right)$, where $R$ is the crack size calculated by the formula: $\lg R=D \lg E+C, K_{0}$ is the minimum energy class of event used in the experiment, $\beta=0.5$. Factor 3 corresponds to the concentration criterion, according to which the critical density of cracks spaced by three times of the crack length accumulates before the macrofracture. At the fracture of the rock specimens, the value of $R_{\text {cr }}$ varied from 1.8 to $3 \mathrm{~mm}$ for all acoustic signals. The authors found that, at the beginning of loading, the signal hypo- 
centres arose randomly in the specimen volume, and after reaching the maximum load, the hypocentre localization occurred in the area of future macrorupture. Furthermore, it was shown that, when approaching to macrorupture, the acoustic activity of clusters increases and activity of single signals decreases. In this work, the direct measurements of the crack lengths were not carried out, and the authors did not compare the concentration criterion values on the data of both acoustic emission and direct measurements. According to preliminary authors' estimates, the concentration criterion for these tests varies from 3 to 5 .

Concentration criterion of crack accumulation was tested for seismic regime description of the seismoactive Kamchatka zone and other regions; based on the implemented assessments, the maps of this criterion changes were plotted [18]. The authors noted another important and informative parameter indicating the earthquake approaching, namely, the area of the accumulated faults, which is estimated as the difference between the accumulated area of seismogenic ruptures over the last year and the average annual value of the area. The epicentres of strong earthquakes practically coincide with the locations of the parameter maxima.

The $k$-criterion dependences on the damaged surface portion of the metal specimens shown in Figs. 2, $d$ and $4, d$ confirm this relationship.

The general tendency to decreasing concentration criterion with increase in deformation observed for ductile (metals) and brittle (rocks) materials appears to reflect the general physical regularity associated with defects' coalescence at pre-fracture stage. The differences in the properties and microstructures of the studied materials have an effect on a change in the values of the $k$-parameter corresponding to a given deformation, i.e., in the position of the estimated value of the $k$ parameter on its dependence on deformation.

3. Apparently, the observed change in the microcracks' distribution functions on length before a critical event connected with the localized crack appearance is the condition of transition from one hierarchical level of fracture process to the next one because of the previous defects' coalescence. Similar change in the defects' distribution function is observed at multiple fractures under dynamic and cyclic loading conditions.

Considering the fragmentation process of the material as caused by extensive influence of independent centres, A. N. Kolmogorov [19] showed that, regardless of fragmentation mechanism, this process in the limiting case leads to a log-normal (i.e., exponential) particle size distribution. For such a case, the process must satisfy two conditions: the different parts of the body are fragmented independently on each other, and the fragment sizes are proportional to the process time.

At the initial stage of fracture, the damage accumulation process 
characterized by the appearance of single microcracks with length substantially smaller than a grain size probably corresponds to such conditions.

The established fact of the change in microcracks' distribution functions, having deep fundamentals and being a common feature of many processes prior to the critical event appearance, is supported by known Ising model describing the phase transition in magnetic systems. The model considers a magnetic material consisting of particles with positive and negative spins. The force of interaction between the particles is limited by the nearest neighbours, and the magnetic polarization of the system is determined by the amount of spins. The scheme in Fig. 6 [20] illustrates the behaviour of such system as a function of temperature in the absence of an applied magnetic field.

At $T=0 \mathrm{~K}$, all the particles have a positive $\left(M=M_{0}\right)$ or negative $\left(M=-M_{0}\right)$ spins. For $T>T_{\mathrm{C}}$, the system is completely random and nonmagnetic. The temperature increases over time. If, at $T=0 \mathrm{~K}$, all the particles have a positive spins, then, at the low finite temperature (point 1 in Fig. 6, $a$ ), the clusters of particles with a negative spin form randomly, without spatial correlation, and the particle clusters' distribution on area corresponds to an exponential distribution (Fig. 6, b). Near the critical temperature (point 2), the clusters of particles with a negative spin become correlated, and a power-law (fractal) cluster distribution on area appears. In this transition region below the critical temperature $\left(T<T_{\mathrm{C}}\right)$, the magnetic polarization obeys a power-law relation $M \propto\left(T_{\mathrm{C}}-T\right)^{\alpha}$, and the particle clusters' distribution is illustrated by the scheme in Fig. $6, c$. At $T=T_{\mathrm{C}}$, magnetic polarization occurs

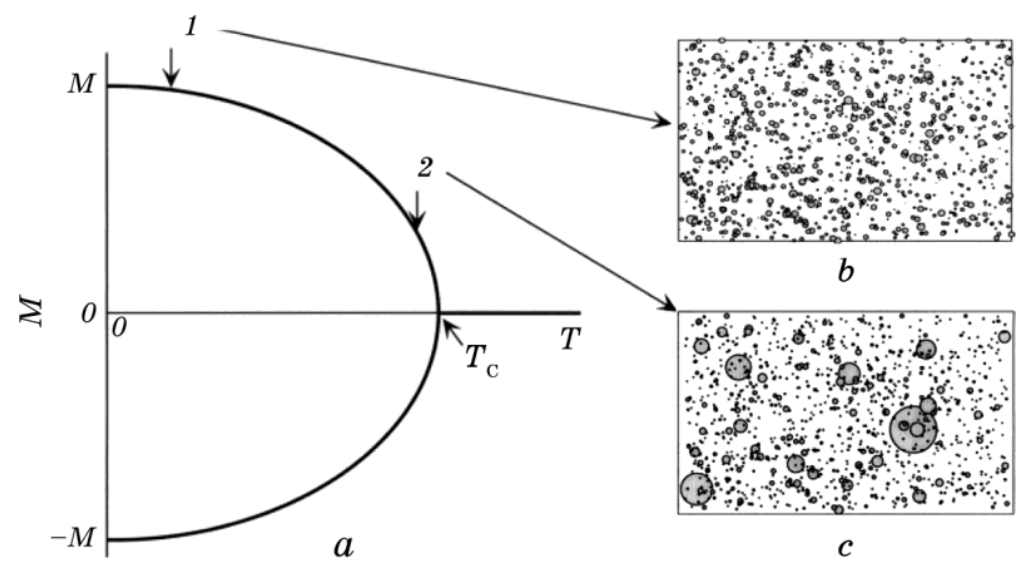

Fig. 6. Temperature dependence of the magnetic moment $(M)$ for the Ising model $(a)$, exponential cluster distribution on area with a negative magnetic moment at point $1(b)$, and power-law distribution in point $2(c)$ near the critical point of the second-order phase transition at $T=T_{\mathrm{C}}[20]$. 
$\left(M \rightarrow 0\right.$ at $\left.T \rightarrow T_{\mathrm{C}}\right)$.

4. Coalescence of cracks at their interaction characterized by the critical value of $k$-parameter can probably be considered from the point of coagulation theory described on the basis of the Boltzmann and Smoluchowski equations. It follows from [21, 22], the authors of which pay attention to the possibility of using the Smoluchowski equation to describe the physical kinetics of different coagulation processes, including, in particular, the formation of microstructure in polycrystalline materials and processes of cracks' growth due to their intercrossing (coagulation) at the macrocrack formation and fracture. According to V. A. Galkin [21], the coagulation 'is directly related to the problems of both the fracture dynamics of structural parts and the prediction of defect development in order to prevent possible accidents'.

\section{CONCLUSIONS}

1. The concentration criterion of fracture characterizing the predominant mechanism of damage development at different stages of static and cyclic loading (accumulation at $k>3$ or coalescence at $k<3$ ) was estimated. Under cyclic loading of specimens of low-carbon steel, the power-law dependence of $k$-parameter on relative durability was found.

2. Under static and cyclic loading of low-carbon steel, the exponential function approximating the cumulative microcracks' distribution curves at the initial loading stage changes by the power-law function at the pre-fracture stage.

3 . The power-law $k$-parameter dependences on both the damaged surface portion and the specific work of plastic deformation were found for the three structural steels under tension.

4. Some general regularities of defect accumulation on different scale levels were considered.

The Russian Science Foundation (project No. 15-19-00237) supported this study.

\section{REFERENCES}

1. S. N. Zhurkov, V.S. Kuksenko, and A. I. Slutsker, Fizika Tverdogo Tela, 11, No. 1: 296 (1969) (in Russian).

2. S. N. Zhurkov, V.S. Kuksenko, V. A. Petrov, V. N. Savel'ev, and U. S. Sultanov, Fizicheskie Protsessy v Ochagakh Zemletryaseniy [Physical Processes of Earthquake Source] (Eds. M. A. Sadovskiy and V. I. Myachkina) (Moscow: Nauka: 1980), p. 78 (in Russian).

3. V. V. Panasyuk and B. L. Lozovyy, DAN UkrSSR, No. 11: 1444 (1962) (in Ukrainian). 
4. $\quad$ V. V. Panasyuk, Predel'noe Ravnovesie Khrupkikh Tel s Treshchinami [Limit Equilibrium of Brittle Solids with Cracks] (Kiev: Naukova Dumka: 1968) (in Russian).

5. T. L. Chelidze, Pure Appl. Geophys., 124, Nos. 4-5: 731 (1986).

6. V.P. Tamuzh and V.S. Kuksenko, Mikromekhanika Destruktsii Polimernykh Materialov [Micromechanics of Destruction of Polymeric Materials] (Riga: Zinātne: 1978) (in Russian).

7. L. R. Botvina, A. P. Soldatenkov, and M. R. Tyutin, Dokl. Earth Sci., 446, No. 1: 1127 (2012).

8. L. R. Botvina, N. A. Zharkova, M. R. Tyutin, A. P. Soldatenkov, Yu. A. Demina, and V. P. Levin, Zavodskaya Laboratoriya. Diagnostika Materialov, 79, No. 5: 46 (2013) (in Russian).

9. L. R. Botvina, M. R. Tyutin, T. B. Petersen, V. P. Levin, A. P. Soldatenkov, and Yu. A. Demina, Russian Metallurgy (Metally), 2017, No. 1: 10 (2017).

10. C. M. Suh, R. Yuuki, and H. Kitagawa, Fatigue Fract. Eng. M, 8, No. 2: 193 (1985).

11. L. R. Botvina, I. M. Rotvayn, V. I. Keylis-Borok, and I. B. Oparina, Doklady $R A N, 345$, No. 6: 809 (1995) (in Russian).

12. L. R. Botvina, Razrushenie: Kinetika, Mekhanizmy, Obshchie Zakonomernosti [Fracture: Kinetics, Mechanisms, General Regularities] (Moscow: Nauka: 2008) (in Russian).

13. I. Rotwain, V. Keilis-Borok, and L. Botvina, Phys. Earth Planet. In., 101, Nos. 1-2: 61 (1997).

14. L. R. Botvina, I. B. Oparina, and O. V. Novikova, Met. Sci. Heat Treat., 39, Nos. 3-4: 151 (1997).

15. L. R. Botvina, I. M. Petrova, I. V. Gadolina, V. P. Levin, Yu. A. Demina, A. P. Soldatenkov, and M. P. T'utin, Inorg. Mater., 46, No. 14: 1570 (2010).

16. B. Gutenberg and C. F. Richter, Seismicity of the Earth and Associated Phenomena (Princeton, New Jersey: Princeton University Press: 1949).

17. I. G. Main, S. Peacock, and P. G. Meredith, Pure Appl. Geophys., 133, No. 2: 283 (1990).

18. G. A. Sobolev and A. V. Ponomarev, Fizika Zemletryaseniy i Predvestniki [Physics of Earthquakes and Precursors] (Moscow: Nauka: 2003) (in Russian).

19. A. N. Kolmogorov, DAN USSR, 31, No. 2: 99 (1941) (in Russian).

20. J. B. Rundle, W. Klein, D. L. Turcotte, and B. D. Malamud, Pure Appl. Geophys., 157, No. 11: 2165 (2000).

21. V. A. Galkin, Analiz Matematicheskikh Modeley: Sistemy Zakonov Sokhraneniya, Uravneniya Boltsmana i Smolukhovskogo [Analysis of Mathematical Models: Set of Conservation Laws, the Boltzmann and Smoluchowski Equations) (Moscow: BINOM, Laboratoriya Znaniy: 2011) (in Russian).

22. S. V. Shevchenko, Nanosistemi, Nanomateriali, Nanotehnologii, 13, No. 2: 371 (2015) (in Russian). 